\title{
GPS observations of coseismic deformation following the May 20 and 29, 2012, Emilia seismic events (northern Italy): data, analysis and preliminary models
}

\author{
Enrico Serpelloni ${ }^{1,{ }^{\star}}$, Letizia Anderlini ${ }^{2,4}$, Antonio Avallone ${ }^{1}$, Valentina Cannelli ${ }^{3}$, Adriano Cavaliere ${ }^{2}$, \\ Daniele Cheloni ${ }^{1}$, Ciriaco D'Ambrosio ${ }^{1}$, Elisabetta D'Anastasio ${ }^{1}$, Alessandra Esposito ${ }^{1}$, \\ Grazia Pietrantonio $^{1}$, Anna Rita Pisani ${ }^{1}$, Marco Anzidei ${ }^{1}$, Gianpaolo Cecere ${ }^{1}$, Nicola D'Agostino ${ }^{1}$, \\ Sergio Del Mese ${ }^{1}$, Roberto Devoti ${ }^{1}$, Alessandro Galvani ${ }^{1}$, Angelo Massucci ${ }^{1}$, Daniele Melini ${ }^{3}$, \\ Federica Riguzzi ${ }^{1}$, Giulio Selvaggi ${ }^{1}$, Vincenzo Sepe ${ }^{1}$
}

\footnotetext{
${ }^{1}$ Istituto Nazionale di Geofisica e Vulcanologia, Centro Nazionale Terremoti, Italy

${ }^{2}$ Istituto Nazionale di Geofisica e Vulcanologia, Sezione di Bologna, Bologna, Italy

${ }^{3}$ Istituto Nazionale di Geofisica e Vulcanologia, Sezione Roma 1, Roma, Italy

${ }^{4}$ Università di Bologna, Dipartimento di Fisica, Settore di Geofisica, Bologna, Italy
}

\section{Article history}

Received July 25, 2012; accepted August 31, 2012.

Subject classification:

Crustal deformations, Measurements and monitoring, Earthquake source and dynamics, GPS, Coseismic deformation, Emilia sequence.

\section{Introduction}

In May-July 2012, a seismic sequence struck a broad area of the Po Plain Region in northern Italy. The sequence included two $M_{L}>5.5$ mainshocks. The first one $\left(M_{L} 5.9\right)$ occurred near the city of Finale Emilia (ca. $30 \mathrm{~km}$ west of Ferrara) on May 20 at 02:03:53 (UTC), and the second $\left(M_{L} 5.8\right)$ occurred on May 29 at 7:00:03 (UTC), about $12 \mathrm{~km}$ southwest of the May 20 mainshock (Figure 1), near the city of Mirandola. The seismic sequence involved an area that extended in an $\mathrm{E}-\mathrm{W}$ direction for more than $50 \mathrm{~km}$, and included seven $\mathrm{M}_{\mathrm{L}} \geq 5.0$ events and more than $2,300 \mathrm{M}_{\mathrm{L}}>1.5$ events (http:/ / iside.rm.ingv.it). The focal mechanisms of the main events [Pondrelli et al. 2012, Scognamiglio et al. 2012, this volume] consistently showed compressional kinematics with E-W oriented reverse nodal planes.

This sector of the Po Plain is known as a region characterized by slow deformation rates due to the northwards motion of the northern Apennines fold-and-thrust belt, which is buried beneath the sedimentary cover of the Po Plain [Picotti and Pazzaglia 2008, Toscani et al. 2009]. Early global positioning system (GPS) measurements [Serpelloni et al. 2006] and the most recent updates [Devoti et al. 2011, Bennett et al. 2012] recognized that less than $2 \mathrm{~mm} / \mathrm{yr}$ of SW-NE shortening are accommodated across this sector of the Po Plain, in agreement with other present-day stress indicators [Montone et al. 2012] and known active faults [Basili et al. 2008].

In the present study, we describe the GPS data used to study the coseismic deformation related to the May 20 and 29 mainshocks, and provide preliminary models of the two seismic sources, as inverted from consensus GPS coseismic deformation fields.

\section{Available GPS data}

In and around the epicentral area, several continuous GPS (cGPS) stations managed by different private and public institutions were operating before and after the seismic sequence that started on May 20. Figure 1 shows the distribution of these cGPS stations and their affiliations, together with the instrumental seismicity recorded after May 20. With the exclusion of the cGPS stations at Concordia sul Secchia (CONC), for which the last data available before the May 20 mainshock was on April 19 all of these stations recorded data continuously across the May 20 mainshock. This allowed for direct measurements of the three-dimensional coseismic displacement of the Earth surface.

Within two days of the May 20 mainshock, we installed six GPS units on existing benchmarks belonging to the IGM95 network (http:/ / www.igmi.org/geodetica) of the Italian Istituto Geografico Militare (IGM; Military Geographic Institute). This choice was related to difficulties in installing new GPS stations in an area characterized by unconsolidated soils and by the absence of a shallow rock basement, and the need for the collection of post-seismic data as rapidly as possible. We chose the IGM95 points (see Figure 1) based on their positions 

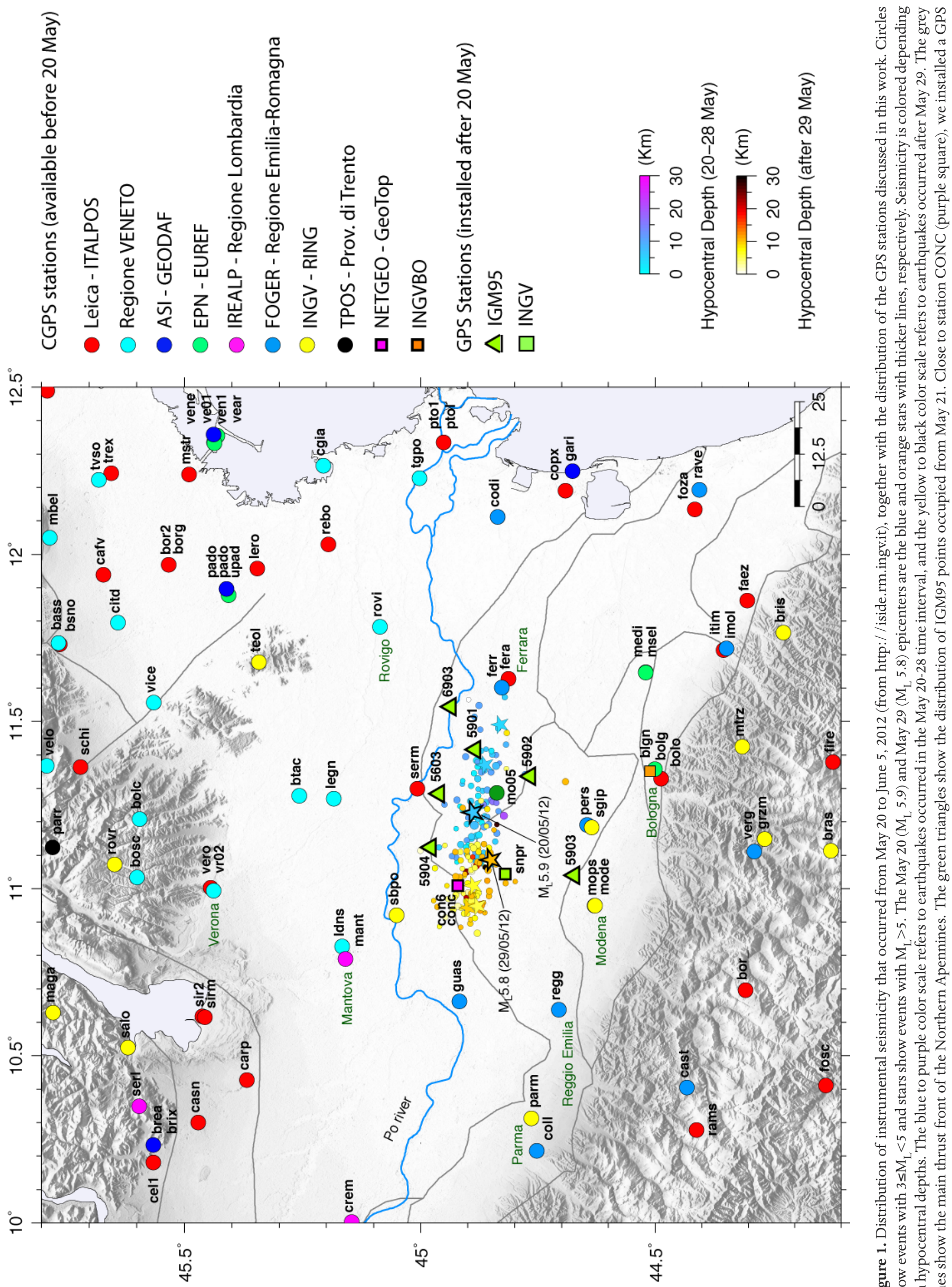

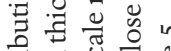

苞亮岕元自

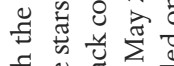

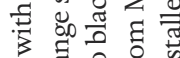

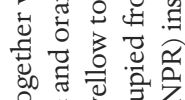
$\stackrel{2}{\circ}$ 己ु

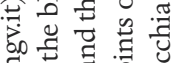
घี

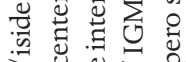

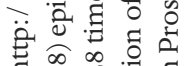

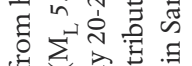
ㄱำ

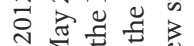
in $\sum_{0} \equiv$

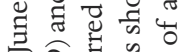

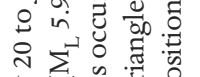

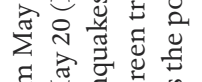

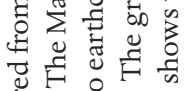

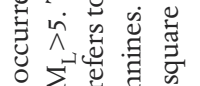

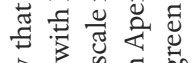

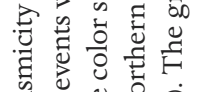

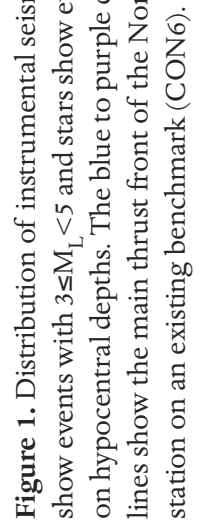


with respect to the May 20 epicenter and taking into account the monument descriptions from the IGM log sheets. Unfortunately, the number of relatively good quality IGM95 benchmarks in the area was rather limited. The green triangles in Figure 1 show the distribution of the IGM95 points measured after May 20. With the exclusion of the point at Nonantola (5903), which was disinstalled before May 29 because of clear increasing instability of the antenna mount with respect to the geodetic benchmark, the other five IGM95 stations recorded continuously across the May $29 \mathrm{M}_{\mathrm{L}} 5.8$ mainshock. After May 29 another two points were installed in the western sector of the aftershock area (Figure 1, SNPR and CON6).

It is worth noting that many of the cGPS stations were collecting data at higher sampling rates than the standard $30 \mathrm{~s}$ (at sampling frequencies from $1 \mathrm{~Hz}$ to $20 \mathrm{~Hz}$ ), and they recorded the dynamic displacements related to the two mainshocks over a wider area in northern Italy [Avallone et al. 2012, this volume].

The daily, 30-s-sampling, RINEX files of the Istituto Nazionale di Geofisica e Vulcanologia (INGV; National Institute of Geophysics and Volcanology) Rete Integrata Nazionale GPS (National Integrated GPS Network) stations and of the IGM stations occupied after May 20 described and used in the present study are available at the following anonymous ftp address: ftp://gpsfree.gm.ingv.it/emilia2012/static.

\section{GPS data analysis}

The available GPS data in the form of 24-h, 30-s-sampling, RINEX files, were processed by three different GPS data-analysis groups using different software and analysis procedures. It is worth noting that several aspects can affect the level of daily repeatability for different geodetic solutions (e.g., the number of phase ambiguities fixed to integer values, different levels of a-priori constraints on the geodetic parameters, the way the reference framework is realized), thus potentially providing different estimates of the coseismic offsets from separate sets of daily position time-series. This is particularly important when the offsets are small; i.e., of the order of magnitude of the daily repeatability.

Given the small displacements expected at most of the GPS stations (in most cases below the centimeter level), due to the relatively moderate magnitude of the two mainshocks and the distances of most stations from the epicenters, a combination procedure was adopted, with the goal being to minimize any possible systematic processing-dependent errors [see Devoti 2012, this volume], and to realize a single consensus dataset of the coseismic deformations related to the May 20 and 29 mainshocks. In particular, in this study, the GPS data were analyzed using the BERNESE (http: / / www. bernese.unibe.ch), GAMIT (http:/ / www-gpsg.mit.edu/ simon/gtgk) and GIPSY (http:/ / gipsy.jpl.nasa.gov/ orms / goa) software. We refer to Avallone et al. [2010] for more detailed descriptions of the procedures of the three data-analysis groups. The BERNESE analysis was performed using double-difference phase observations with ambiguity resolution, adopting the absolute phase center model, and applying tight constraints on the International Global Navigation Satellite Systems (GNSS) Service (IGS) orbits and Earth orientation parameters (EOPs). The analysis of a wider network was distributed on several subnets, realizing the International Terrestrial Reference Frame (ITRF)08 position-time series using a set of 10 core stations located in Europe. The GAMIT analysis was performed using double-difference phase observations with ambiguity resolution, adopting the absolute phase center model for receiver and satellite antennas, although in this case the IGS orbits and EOPs were loosely constrained and re-estimated together with the station positions, realizing the ITRF08 position-time series using the global IGS08 core stations as internal constraint stations. The GIPSY analysis was performed using the precise point positioning strategy (module gd2p.pl, GIPSY, version 6.1) developed at the Jet Propulsion Laboratory (JPL, California, USA), which includes absolute antenna phase center modeling and ambiguity resolution [Bertiger et al. 2010]. By using the JPL final fiducial orbits and clocks, the position time series was obtained directly in the ITRF08 reference framework.

The three data-analysis groups provided the ITRF position-time series of daily station positions as SINEX and STACOV files, which were used to independently estimate the three coseismic displacements. Thus, the combination of the individual solutions was obtained by solving for the combined offsets (unknowns) in a least squares sense [see Devoti 2012]. The weighted root mean squares (WRMS) of the differences between the three solutions is $2.1 \mathrm{~mm}$ and $4.2 \mathrm{~mm}$ for the horizontal and vertical components, respectively, for the May 20 event, and $2.6 \mathrm{~mm}$ for both components for the May 29 event.

\section{Coseismic displacement and fault models}

Figure 2 shows the combined horizontal coseismic displacements for the May 20 and 29 mainshocks. The vertical coseismic displacements are presented in Figure 2 only for the May 20 mainshock, where reliable vertical offsets were estimated, while for the May 29 event, no significant vertical patterns were observed. For co-located GPS stations, or groups of stations where the short inter-distance does not justify significantly different coseismic offsets, we constrained these stations to have the same coseismic offset during the least-squares estimate. The coseismic displacement fields, with their related uncertainties, for the May 20 and 29 events are available on-line, as ASCII tables, at the following addresses:

1) ftp://gpsfree.gm.ingv.it/emilia2012/static/Emilia CombinedRed120520_ver4.dat

2) ftp:/ / gpsfree.gm.ingv.it/emilia2012/static/Emilia CombinedRed120529_ver1.dat 


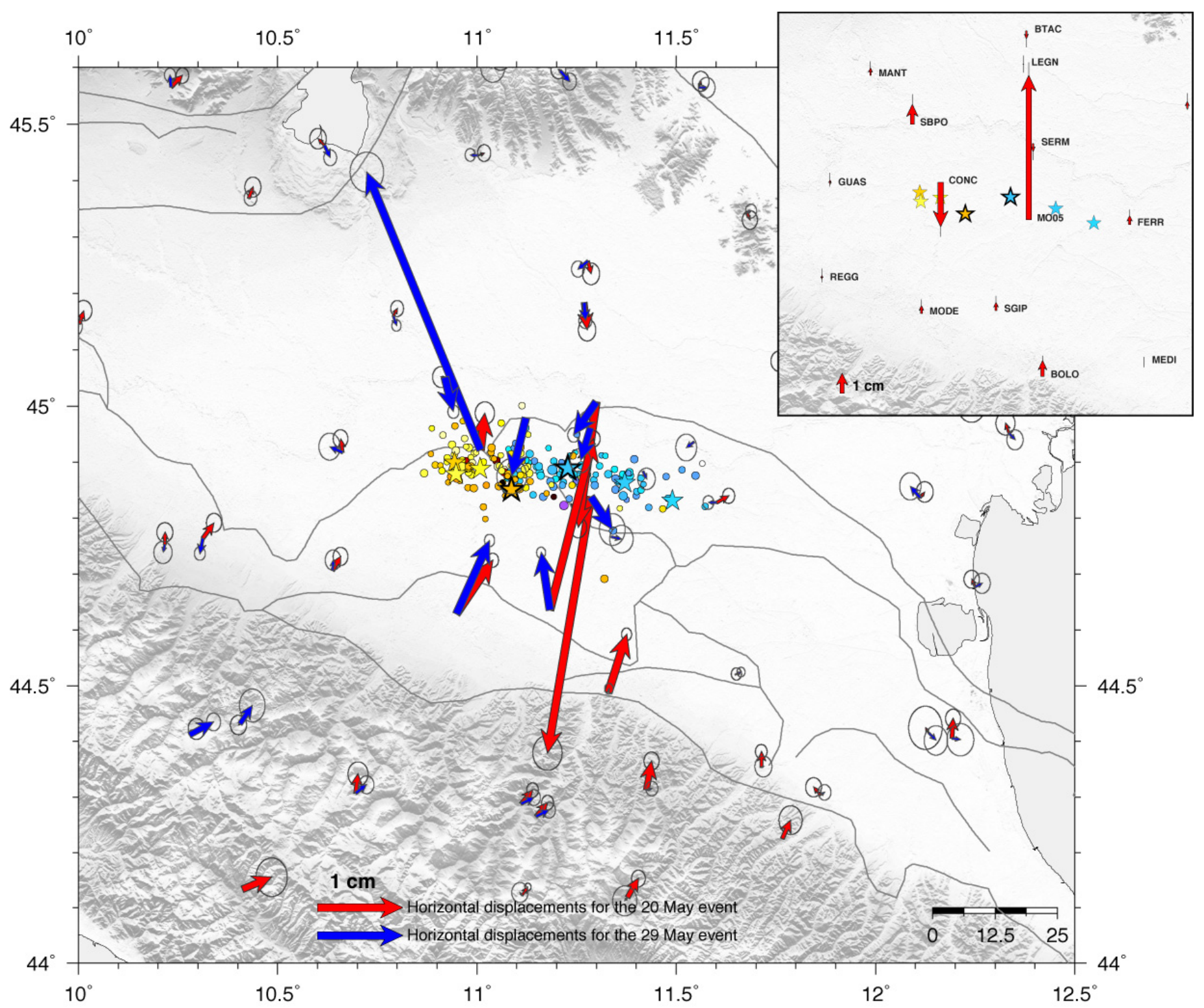

Figure 2. Horizontal coseismic displacements with $68 \%$ error ellipses, as obtained from the combination of the three independent GPS solutions (see Section 2) for the May 20 (red arrows) and May 29 (blue arrows) events. The seismicity is drawn as in Figure 1. Upper-right inset: vertical displacements associated with the May 20 event.

For the May 20 event, the largest displacements were measured at Finale Emilia (MO05), which moved to the SSW by ca. $3 \mathrm{~cm}$ and uplifted by ca. $7 \mathrm{~cm}$. San Giovanni in Persiceto (SGIP, PERS) moved NNE-wards by ca. $2 \mathrm{~cm}$, whereas Sermide (SERM), which was located north of the aftershock distribution, moved southwards by ca. $1.5 \mathrm{~cm}$. The other stations moved horizontally by $<1 \mathrm{~cm}$ in a radius of ca. $50 \mathrm{~km}$ from the epicenter (e.g., Bologna and Modena moved NNEwards by ca. $7 \mathrm{~mm}$ ). We measured reliable vertical displacements $(>1 \mathrm{~cm})$ also at San Benedetto Po (SBPO, ca. $1 \mathrm{~cm})$ and Concordia sul Secchia (CONC, ca. $-2 \mathrm{~cm}$ ). Due to the already mentioned data gap at CONC before May 20, 2012, the coseismic displacements at this station were less constrained than for other sites. The errors associated with the coseismic displacements represent the formal $1 \sigma$ uncertainties of the least-squares estimates [see Devoti 2012, for more details], and were generally $<0.5 \mathrm{~mm}$ in the horizontal com- ponents, while for the vertical component, they were between $1.5 \mathrm{~mm}$ and $4.0 \mathrm{~mm}$.

For the May 29 event, we measured coseismic displacements at a greater number of sites, as data was also available from the IGM95 stations installed soon after the May 20 event, although the displacements were in general smaller than for the May 20 event. They were also all $<1 \mathrm{~cm}$ in the horizontal components, with the exception of CONC, which was close to the epicenter of the May 29 mainshock.

It is worth noting that all of the GPS stations discussed in this study were mounted on buildings or on small manmade concrete infrastructures, although of different natures. For the two stations closest to the two mainshock epicenters, MO05 and CONC, after visual inspections of the GPS monuments, we found significant damage only to the building hosting the CONC antenna, which was damaged after the May 29 mainshock, and for this reason this station 


\begin{tabular}{|c|c|c|c|c|c|c|c|c|c|c|c|}
\hline 20 May & $\begin{array}{l}\text { Length } \\
(\mathrm{km})\end{array}$ & $\begin{array}{l}\text { Width } \\
(\mathrm{km})\end{array}$ & $\begin{array}{l}\text { Depth }_{\text {Top }} \\
\quad(\mathbf{k m})\end{array}$ & $\begin{array}{l}\text { Depth }_{\text {Bottom }} \\
(\mathbf{k m})\end{array}$ & $\begin{array}{l}\text { Dip } \\
\left({ }^{\circ}\right)\end{array}$ & $\begin{array}{l}\text { Strike } \\
\left({ }^{\circ}\right)\end{array}$ & $\begin{array}{l}\text { CF Lon } \\
\left({ }^{\circ} \mathrm{E}\right)\end{array}$ & $\begin{array}{l}\text { CF Lat } \\
\left({ }^{\circ} \mathbf{N}\right)\end{array}$ & $\begin{array}{l}\text { Slip } \\
(\mathrm{cm})\end{array}$ & $\begin{array}{c}\text { Rake } \\
\left({ }^{\circ}\right)\end{array}$ & $\mathrm{M}_{\mathrm{W}}$ \\
\hline INGV1 & $8.7{ }_{6}^{15}$ & $6.5 \frac{12}{6}$ & 5.2 & $9.3{ }_{6}^{14}$ & $38.8_{25}^{50}$ & $106_{95}^{110}$ & $11.293 \begin{array}{l}11.32 \\
11.20\end{array}$ & $44.866_{44.80}^{44.90}$ & 116 (free) & 85.7 (free) & 6.12 \\
\hline INGV2 & $17.3 \frac{35}{5}$ & $4.4 \frac{20}{2}$ & $4.6_{0}^{15}$ & 7.2 & $37.6_{10}^{50}$ & $112_{90}^{130}$ & $11.299 \begin{array}{l}11.73 \\
10.73\end{array}$ & $44.853 \begin{array}{r}45.39 \\
44.39\end{array}$ & $80_{10}^{100}$ & $85.8_{70}^{110}$ & 6.10 \\
\hline INGV3 & $12.5_{5}^{20}$ & $5.0{ }_{5}^{15}$ & $4.9 \stackrel{15}{0}$ & 7.9 & $36.7_{30}^{60}$ & $110{ }_{80}^{110}$ & $11.294_{11.12}^{11.48}$ & $44.857_{44.72}^{45.08}$ & $101_{0}^{102}$ & $86.5{ }_{0}^{180}$ & 6.11 \\
\hline MEAN & 12.8 & 5.3 & 4.9 & 8.1 & 37.7 & 109 & 11.295 & 44.859 & 99 & 86.0 & 6.13 \\
\hline
\end{tabular}

29 May

\begin{tabular}{|c|c|c|c|c|c|c|c|c|c|c|c|}
\hline INGV1 & $9.6 \frac{12}{5}$ & $7.1 \frac{12}{6}$ & 2.4 & $6.3 \frac{10}{6}$ & $33.3_{25}^{45}$ & $102{ }_{90}^{105}$ & $11.075_{10.9}^{11.1}$ & $44.828 \stackrel{44.9}{44.8}$ & 39 (free) & 83.0 (free) & 5.86 \\
\hline INGV2 & $14.2_{5}^{35}$ & $5.0_{2}^{20}$ & $3.0{ }_{0}^{15}$ & 6.0 & $37.5_{20}^{60}$ & $99.6 \frac{125}{65}$ & $11.068_{10.59}^{11.59}$ & $44.806_{44.35}^{45.35}$ & $35 \frac{100}{10}$ & $83.1{ }_{70}^{110}$ & 5.84 \\
\hline INGV3 & $14.3 \frac{15}{5}$ & $5.1{ }_{5}^{15}$ & $2.9 \frac{15}{5}$ & 5.8 & $34.9 \stackrel{50}{25}$ & $104{ }_{95}^{105}$ & $11.069 \begin{array}{l}11.48 \\
11.12\end{array}$ & $44.793 \begin{array}{l}45.08 \\
44.72\end{array}$ & $35 \underset{0}{100}$ & 90 (fixed) & 5.85 \\
\hline MEAN & 12.7 & 5.7 & 2.8 & 6.1 & 35.2 & 102 & 11.071 & 44.809 & 36 & 85.4 & 5.85 \\
\hline
\end{tabular}

Table1. Coseismic fault parameters obtained by the three independent uniform-slip inversions for the May 20 and May 29, 2012, events. Subscript and superscript numbers are the lower and upper bounds of the geometric fault parameters used in the non-linear inversions and, eventually, the bounds of the

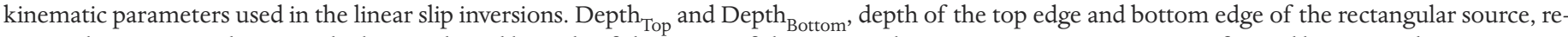
spectively. CF Lon and CF Lat, the longitude and latitude of the center of the rectangular source. INGV1 inversion performed by L.A. and E.S. (at INGV, Sezione di Bologna); INGV2 inversion performed by D.M and V.C. (at INGV, Sezione Roma 1), and INGV3 inversion performed by D.C. (at INGV, Centro Nazionale Terremoti). The MEAN solution was obtained by averaging the parameters values obtained from the three independent inversions. The mean Depth $\mathrm{Bottom}_{\text {and }} \mathrm{M}_{\mathrm{W}}$ are derived from the average (MEAN) values.

has not been used in the further modeling.

A few hours after the May 20 mainshock, different groups started studying the seismic source using the preliminary estimated GPS displacements. In the present study, we report on the results obtained from the three data-analysis groups affiliated with different INGV Departments, with the goal of providing consensus fault models for the May 20 and 29 sources, starting from a shared dataset of coseismic GPS displacements. It is worth noting that the number and distribution of GPS stations, which were particularly missing in the nearsource, did not allow for a reliable study of the variable distributions of the coseismic slip on the fault planes, so we limited our analysis to the inversion of uniform-slip faults.

Table 1 gives the summary of the results obtained by uniform-slip inversions using rectangular dislocations in a uniform half-space [Okada 1985]. After some very preliminary model inversions, the three data-analysis groups adopted similar non-linear inversion algorithms, and particularly those based on simulated-annealing techniques. Inversions performed with no a-priori constraints on the geometric and kinematic parameters show the presence of several local minima and strong parameter correlations. In particular, for the May 20 event the stations with the largest displacements were roughly aligned along a direction nor- mal to the fault strike and crossing the center of the fault (derived from the aftershock distribution), making it difficult to separately resolve the fault, strike and rake. For this reason, a-priori constraints derived from seismological data (e.g., focal solutions, aftershocks distributions) and geological information (e.g, fault databases, seismic lines) were used in the nonlinear inversions. In particular, the dip (towards the south) and the fault strike nonlinear search were limited to realistic ranges for both of the sources. Table 1 shows the lower and upper bounds for each fault parameter that were adopted in the source inversions.

Independent inversions of the combined displacement fields for the May 20 and 29 events provided comparable results (see Table 1 and Figure 3). Small differences among the three fault solutions, however, can result from different tuning of the non-linear inversion algorithms, and from the use of different fault boundaries in the inversions (see Table 1). We provide consensus fault models for both the May 20 and 29 events, through the averaging of the geometric and kinematic parameters that were inverted independently by each of the three data-analysis groups (see Table 1).

For the May 20 event, our study indicates that the mainshock occurred on a $\mathrm{N}$-verging, ca. $38^{\circ} \mathrm{S}$-dipping, ca. $109^{\circ}$ striking fault plane, with a thrusting mechanisms (rake, ca. $89^{\circ}$ ) 

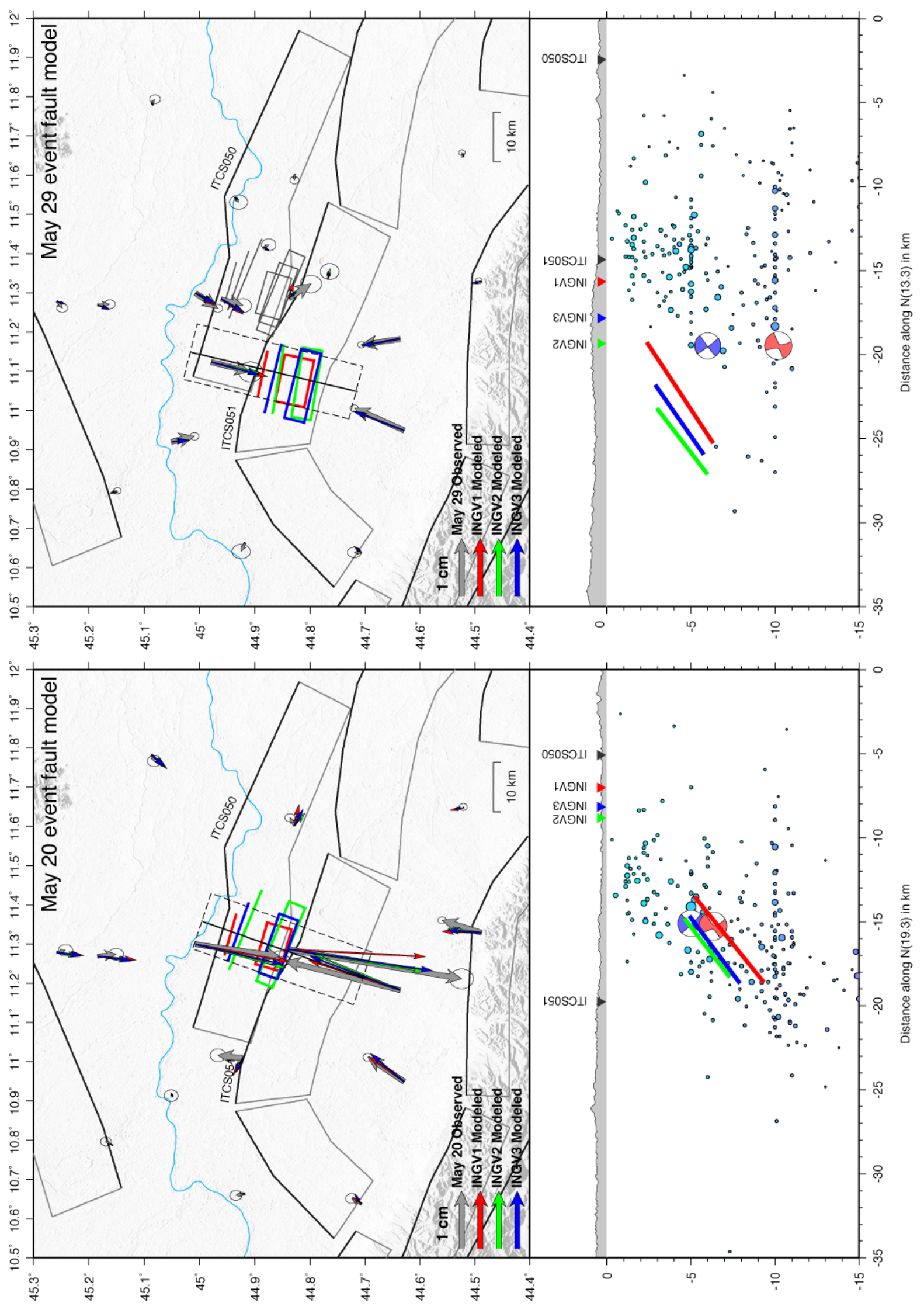

चु है

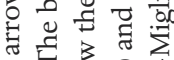

可

답 의

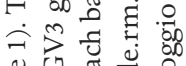

远范

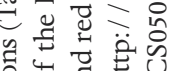

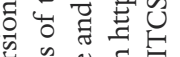

音莺号递焉

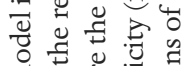

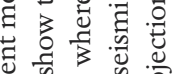

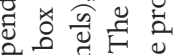

흠

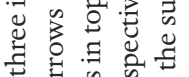

o

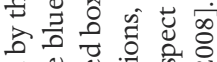

궘

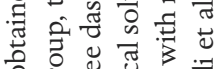

응

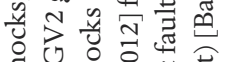

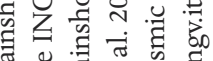

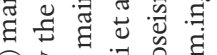

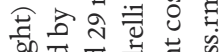

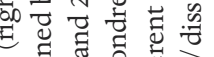

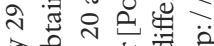

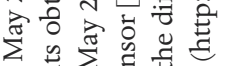

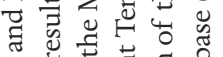

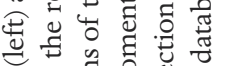

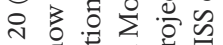

항

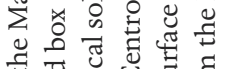

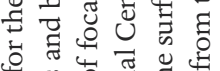

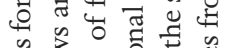

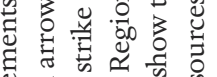

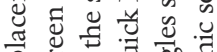

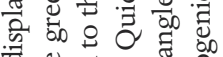

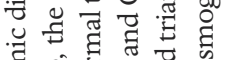

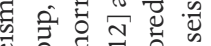

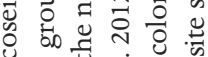

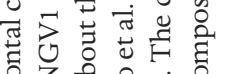

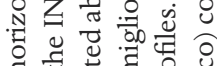

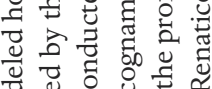

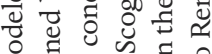

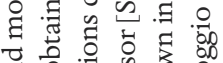

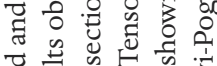

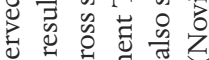

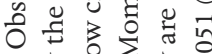

نे क्षे

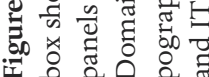


and a slip of ca. $99 \mathrm{~cm}$, confined between about $5 \mathrm{~km}$ and $8 \mathrm{~km}$ in depth, giving $\mathrm{M}_{\mathrm{W}}$ 6.1. The derived source model is in agreement with the distribution of aftershocks and focal solutions (see Figure 3). For the May 29 event, our study indicates that the mainshock occurred on a $\mathrm{N}$-verging, ca. $35^{\circ} \mathrm{S}$-dipping, ca. $102^{\circ}$ striking fault plane, with a thrusting mechanisms (rake, ca. $85^{\circ}$ ) and a slip of ca. $36 \mathrm{~cm}$, confined between about $3 \mathrm{~km}$ and $6 \mathrm{~km}$ in depth, giving $\mathrm{M}_{\mathrm{W}}$ 5.8. The derived fault model is geometrically in agreement with the focal solutions, although offset $\mathrm{SW}$-wards (by ca. $5 \mathrm{~km}$ ) with respect to the distribution of the seismicity with depth (see Figure 3).

\section{Discussion and conclusions}

We have studied the crustal deformation caused by the two mainshocks of the earthquake sequence that started on May 20 in the Emilia Po Plain (northern Italy), as measured by continuous and campaign GPS stations. We have modeled the observed coseismic displacements, provided in terms of the consensus deformation fields obtained from the combination of independent geodetic solutions, through inversions based on elastic deformation theory, using the standard Okada formulation. The availability of GPS stations continuously recording across moderate magnitude earthquakes, although of relatively lower data and monument quality, as the ones installed on the IGM95 benchmarks after the May 20 event, allows accurate (sub-centimeter) estimates of the horizontal coseismic displacements, and provide valuable data to constrain the source faults.

The modeled source faults fit the N-NNE-verging blind thrusts of the external Ferrara-Romagna Arc both geometrically and kinematically. Inversions of the GPS data confirm that the May 20 and 29 earthquakes ruptured two independent segments of this blind structure. The two inverted sources show a gentle counterclockwise rotation of the fault strike, from ca. $109^{\circ}$ to ca. $102^{\circ}$, which is consistent with the rotation of the arc and shows mostly pure reverse faulting kinematics, in agreement with focal mechanisms and known seismotectonic and geological features of the area.

Although preliminary, the source faults inverted from available GPS data can be tentatively associated to segments belonging to the ITCS050 'Poggio Rusco-Migliarino' (for the May 20 event) and a segment of the ITCS051 'Novi-Poggio Renatico' (for the May 29 event) composite seismogenic sources of the Database of Individual Seismogenic Sources. However, while for the May 20 event we find relatively good agreement between the model fault plane and the distribution of the aftershocks, for the May 29 event the modeled fault plane imaged by GPS is shifted by ca. $5 \mathrm{~km}$ to the SW with respect to the crustal volume affected by the aftershocks. The lack of near-source GPS stations (especially for the May 29 event, after the decision not to use the displacements measured at the CONC station, which was the only near-source station available for that event) was certainly a limit on the source inversion. However, it is worth considering that only when better constrained, precisely relocated, aftershocks will be available, will a comparison between space-geodetically derived source faults and seismicity distribution be meaningful.

An integration of the GPS coseismic displacement fields with denser InSAR displacements [eg., Salvi et al. 2012, this volume] is needed to solve for the variable slip distribution on the two fault segments activated during this sequence, and to better understand the geometric relationships between the geodetically derived fault planes, the aftershock distribution with depth, and the known geological structures.

Acknowledgements. We thank all of the public and private institutions that manage and distribute the GPS data used in this study, including: EUREF, ASI, ERSAF-Regione Lombardia, Regione Veneto. We also thank the General Commander G. Petrosino and G. Tomasino of the Istituto Geografico Militare Italiano for the data of the IGM95 network. We thank the Fondazione Geometri e Geometri Laureati dell'Emilia Romagna (FOGER) for providing the Emilia-Romagna GNSS Network, the Department of Earth Sciences of the University of Siena and the Department of Physics of the University of Bologna for providing data from the GPS station in Finale Emilia (MO05), which formerly belonged to the ASSOGEO network. We also thank GeoTop s.r.l., Gruppo Topcon-Sokkia, for providing data from the CONC station, and Leica Geosystems for data from the Italpos GNSS network. Giuseppe Casula is acknowledged for sharing data of the BLGN station. Fabiana Loddo and Nicola Cenni helped in the update of the hardware of the SGIP RING station during the seismic sequence. The manuscript benefited from the thoughtful comments of two anonymous reviewers.

\section{References}

Avallone, A., G. Selvaggi, E. D'Anastasio, N. D'Agostino, G. Pietrantonio, F. Riguzzi, E. Serpelloni, M. Anzidei, G. Casula, G. Cecere, C. D'Ambrosio, P. De Martino, R. Devoti, L. Falco, M. Mattia, M. Rossi, F. Obrizzo, U. Tammaro and L. Zarrilli (2010). The RING network: improvements to a GPS velocity field in the central Mediterranean, Annals of Geophysics, 53 (2), 39-54; doi:10.4401/ag-4549.

Avallone, A., E. D'Anastasio, E. Serpelloni, D. Latorre, A. Cavaliere, C. D'Ambrosio, S. Del Mese, A. Massucci and G. Cecere (2012). High-rate (1 Hz to 20-Hz) GPS co-seismic dynamic displacements carried out during the Emilia 2012 seismic sequence, Annals of Geophysics, 55 (4); doi:10.4401/ag-6162.

Basili, R., G. Valensise, P. Vannoli, P. Burrato, U. Fracassi, S. Mariano, M.M. Tiberti, E. Boschi (2008). The Database of Individual Seismogenic Sources (DISS), version 3: summarizing 20 years of research on Italy's earthquake geology, Tectonophysics; doi:10.1016/j.tecto.2007.04.014.

Bennett, R.A., E. Serpelloni, S. Hreinsdóttir, M.T. Brandon, G. Buble, T. Basic, G. Casale, A. Cavaliere, M. Anzidei, M. Marjonovic, G. Minelli, G. Molli and A. Montanari (2012). Syn-convergent extension observed using the RETREAT GPS Network, northern Apennines, Italy, J. Geophys. Res., 117; doi:10.1029/2011JB008744.

Bertiger, W., S. Desai, B. Haines, N. Harvey, A. Moore, S. 
Owen and J. Weiss (2010). Single receiver phase ambiguity resolution with GPS data, J. Geodesy, 84, 327-337.

Devoti, R., A. Esposito, G. Pietrantonio, A.R. Pisani and F. Riguzzi (2011). Evidence of large-scale deformation patterns from GPS data in the Italian subduction boundary, Earth Planet. Sci. Lett., 311, 1-12; doi:10.1016/j.epsl.2011. 09.034 .

Devoti, R. (2012). Combination of coseismic displacement fields: a geodetic perspective, Annals of Geophysics, 55 (4); doi:10.4401/ag-6119.

Montone, P., M.T. Mariucci and S. Pierdominici (2012). The Italian present-day stress map, Geophys. J. Int., doi:10.1111 /j.1365-246X.2012.05391.x.

Okada, Y. (1985). Surface deformation due to shear and tensile faults in a half-space, B. Seismol. Soc. Am., 75, 1135-1154.

Picotti, V., and F.J. Pazzaglia (2008). A new active tectonic model for the construction of the northern Apennines mountain front near Bologna (Italy), J. Geophys. Res., 113; doi:10.1029/2007JB005307.

Pondrelli, S., S. Salimbeni, P. Perfetti and P. Danecek (2012). Quick regional centroid moment tensor solutions for the Emilia 2012 (northern Italy) seismic sequence, Annals of Geophysics, 55 (4); doi:10.4401/ag-6146.

Salvi, S., C. Tolomei, J.P. Merryman Boncori, G. Pezzo, S. Atzori, A. Antonioli, E. Trasatti, R. Giuliani, S. Zoffoli and A. Coletta (2012). Activation of the SIGRIS monitoring system for ground deformation mapping during the Emilia 2012 seismic sequence, using COSMO-SkyMed InSAR data, Annals of Geophysics, 55 (4); doi:10.4401 /ag-6181.

Scognamiglio, L., L. Margheriti, F.M. Mele, E. Tinti, A. Bono, P. De Gori, V. Lauciani, F.P. Lucente, A.G. Mandiello, C. Marcocci, S. Mazza, S. Pintore and M. Quintiliani (2012). The 2012 Pianura Padana Emiliana seimic sequence: locations, moment tensors and magnitudes, Annals of Geophysics, 55 (4); doi:10.4401/ag-6159.

Serpelloni, E., M. Anzidei, P. Baldi, G. Casula and A. Galvani (2006). GPS measurement of active strains across the Apennines, Annals of Geophysics, Supplement to vol. 49 (1), 319-329.

Toscani, G., P. Burrato, D. Di Bucci, S. Seno and G. Valensise (2009). Plio-Quaternary tectonic evolution of the northern Apennines thrust fronts (Bologna-Ferrara section, Italy): seismotectonic implications, B. Soc. Geol. Ital., 128, 605-613; doi:10.3301/IJG.2009.128.2.605.

\footnotetext{
${ }^{\star}$ Corresponding author: Enrico Serpelloni, Istituto Nazionale di Geofisica e Vulcanologia, Centro Nazionale Terremoti, c/ o Sezione di Bologna, Italy; email: serpelloni@bo.ingv.it. 